\title{
Position sense and state of contraction; the effects of vibration
}

\author{
G. EKLUND
}

From the Department of Clinical Neurophysiology, University Hospital, Uppsala, Sweden

SUMMARY The position sense of the knee joint was investigated in normal subjects lying in the supine position with both legs hanging freely. Three different manoeuvres were used to bring one leg into an extended position: voluntary activation of the quadriceps muscle, reflex activation of the quadriceps (TVR) and passive lifting of the leg. For each manoeuvre the subjects indicated with the other limb their perception of the joint position. It was found that the position produced by voluntary contraction was correctly perceived, that of the TVR was underestimated, and that of passive lifting was overestimated. The findings indicate that receptors in limb muscles may be used to judge limb position in addition to joint receptors and sense of effort. The findings are supported by repeated observations that muscle vibration can cause movement-illusions during isometric conditions.

Cohen, who analysed the position sense of the human shoulder in terms of error when trying to reproduce a pointing position with fully extended arm (1958a), regarded position sense as chiefly dependent on articular receptors but with significant and independent contributions from both tactile and musculo-tendinous receptors (1958b). The sensation of movement and position at the metatarsophalangeal joint of the great toe in man was studied by Browne, Lee, and Ring (1954). They found that local anaesthesia of the joint capsule gave rise to loss of appreciation of both movements and of position sense. On the other hand, they made a distinction between active and passive movements : the active movements ' would appear in addition to be indicated by impulses from muscles and tendons'. In similar experiments on the index finger (Provins, 1958) active movement sense was greatly impaired, although the receptors in muscles and tendons were intact. In reviews of these and allied matters, Merton (1964, 1970) pointed out that 'it appears that limb muscles, like eye and tongue muscles, are insentient'. According to him, it is the sense of effort that is responsible for the impressions of movement and position when information from joint and periarticular receptors are excluded. The appurtenant proprioceptors in the muscle would not participate in the production of such impressions. In addition, Gelfan and? Carter (1967) who pulled on muscle tendons under local anaesthesia concluded that there is no 'muscle sense'. Unfortunately, they did not? pull against a voluntary contraction.

The present study was initiated by repeatedo findings that illusions of movement were experienced during experiments with muscle vibration. Thus, mechanical stimulation of muscle receptors can give rise to movement-illusions (length changes) indicating that these receptors might be able to signal steady length - that is, position. These matters were incidentally reported by Hagbarth and Eklund (1966): despite the subject's knowledge of the rigid, isometric conditions a feeling of joint rotation could become apparent but could also vanish in an uncontrollable way. At times, illusions of movements of the floor and feet have been noted in connection with vibration experiments related to the study of neurophysiological control of balance and posture (Eklund, 1969; Eklund and Löfstedt, 1970).

The purpose of the present experiments was to investigate if a vibration-induced contraction did affect position sense in a systematic way. It was not intended, however, to establish normal 
values for position sense in the various test situations.

\section{METHODS}

Nine healthy adults, 18 to 30 years of age, were tested. Subjects lay in the supine position on a bench with the legs hanging freely over the edge. They were instructed to look at the ceiling or to have the eyes closed. Two potentiometers, firmly attached to the bench were used to record knee joint position. They faced each other and had coincident axes which corresponded to the common transverse axis of the knee joints. Thin steel rods attached to the potentiometers ran parallel with the legs for $35 \mathrm{~cm}$ where they were bent at right angles so that they rested against the anterior aspect of the shin. The signals from these goniometers were recorded on separate channels of an FM-tape recorder (PI-6200), together with their difference and a signal from a hand-held indicator.

The events in time order during an experiment were as follows: from the resting position (knee angles about $100^{\circ}$ ) one leg was changed to a position in the range of $120^{\circ}-150^{\circ}$. This leg, regardless of left or right, will henceforth be called the first leg. After an interval of about $10-15 \mathrm{sec}$ the subject, according to previous instructions, attempted to reproduce this position with his other leg (henceforth called second leg), and signalled when he felt that both joints were at the same position. This was the basic test situation. The first leg was brought to its position by three different procedures-namely: (1) voluntary contraction (henceforth VOL); (2) lifting by the experimenter during passivity on behalf of the subject (henceforth PAS); (3) TVR (tonic vibration reflex) - that is, an involuntary, vibration-induced contraction (Eklund and Hagbarth, 1966).

The vibration used (Eklund, 1971) had a peak-topeak displacement (amplitude) of $1.8 \mathrm{~mm}$ and a frequency of about $160 \mathrm{~Hz}$. In order to elicit a TVR, a vibrator was fastened with strong rubber bands over the patellar ligament, or, if this placement evoked too strong a contraction $\left(150^{\circ}-180^{\circ}\right)$, just proximal to the patella which is somewhat less effective in eliciting TVR in the knee extensors. Further experimental details are described along with the results.

\section{RESULTS}

GENERAL OBSERVATIONS Nine subjects were tested to see if any obvious patterns of reaction would emerge. It soon became evident that all subjects accurately indicated a position to which the first leg had moved actively (VOL). On visual inspection it was generally hard to detect any difference between the limbs when the subject was content with his task. Such tasks were performed without hesitation.

The next procedure was to lift the first leg passively into position (PAS). The examiner carefully, and as steadily as possible, applied pressure with his hand behind the heel, thereby bringing the leg into position. Initially and in between the tests, repeated slow or quick oscillatory movements were performed in order to assess that good relaxation prevailed. This was also a necessary complement to the verbal instructions regarding relaxation. Seven of the subjects moved the second leg to a higher, more extended position (overshoot). These subjects often lifted the second leg $5 \mathrm{~cm}$ higher than the first as measured at the heels, corresponding to an angle difference of about $6^{\circ}$. The other two subjects were more accurate, there being no overshoot. These persons had, however, great difficulty in relaxing and a slight unconscious contraction in the first leg could not be excluded. In fact, sometimes in subjects with initially good relaxation and obvious overshoot, the experimenter suddenly noted a slight reduction in the pressure against his palm, indicating an unintentional contraction of the quadriceps muscle and, at the same time, the subject corrected the position of his second leg or stated that he now realized that it was much too high.

In the third experimental situation vibration of the quadriceps muscle was used to evoke a TVR strong enough to keep the leg extended against gravity and within the test range. As a rule, a clear undershoot appeared in the second leg-that is, the contrary to what happened during PAS.

NONSPECIFIC VIBRATION Vibrators were applied to each side of the knee joint of the first leg during the VOL and PAS testing procedures. This manoeuvre was undertaken in an attempt to excite skin and capsular sensory endings in a nonspecific way. It was necessary to have thin foam plastic cushions beneath the vibrators at the site of application to avoid uncomfortable stimulation of bone structures. These manoeuvres did not notably alter the general findings of overshoot during PAS and good imitation during VOL. 
MEASUREMENT In order to obtain a numerical estimate of the observations, one subject was chosen for measurement. He had performed typically during the previous observations without being a representative of those who showed the most apparent over- and undershootings. A total of 50 trials was obtained for each of the basic test situations - that is, VOL, PAS, and TVR. The corresponding procedure was also performed for VOL and PAS in combination with the nonspecific vibration $(\mathrm{V}+$ and $\mathrm{P}+$ in the Figure). For VOL and PAS the first leg was kept in the same position during 10 estimations with the second leg. After a short rest period, the procedure was repeated. Thus, these tests were performed in five groups of 10 trials each; for TVR, 10 groups of five trials each were executed instead. This was necessary, since the upper row contains a "cluster of 50 angle-differences' for each of the tests. This was photographed on standing film; below is shown the 10 first trials of VOL, PAS, and TVR using a higher gain and a slowly moving film. The oscilloscope trace had been partly covered to facilitate determination of chronological order. The following values (average/SD) were obtained: VOL, $0 \cdot 12^{\circ} / 2 \cdot 86^{\circ}$; PAS, $6.42^{\circ} / 1 \cdot 67^{\circ}$; and TVR, $-1.92^{\circ} /$ $2 \cdot 86^{\circ}$. The average for the 10 first TVR-trials was $-3 \cdot 74^{\circ}$.

VIBRATION OF KNEE MUSCLES OF SECOND LEG During VOL-experiment the extensor or flexor muscles of the second leg were vibrated. When the voluntary extension of this leg took place $\%$ together with vibration of the quadriceps muscle $\overrightarrow{0}$ on that side, a tendency toward overshooting

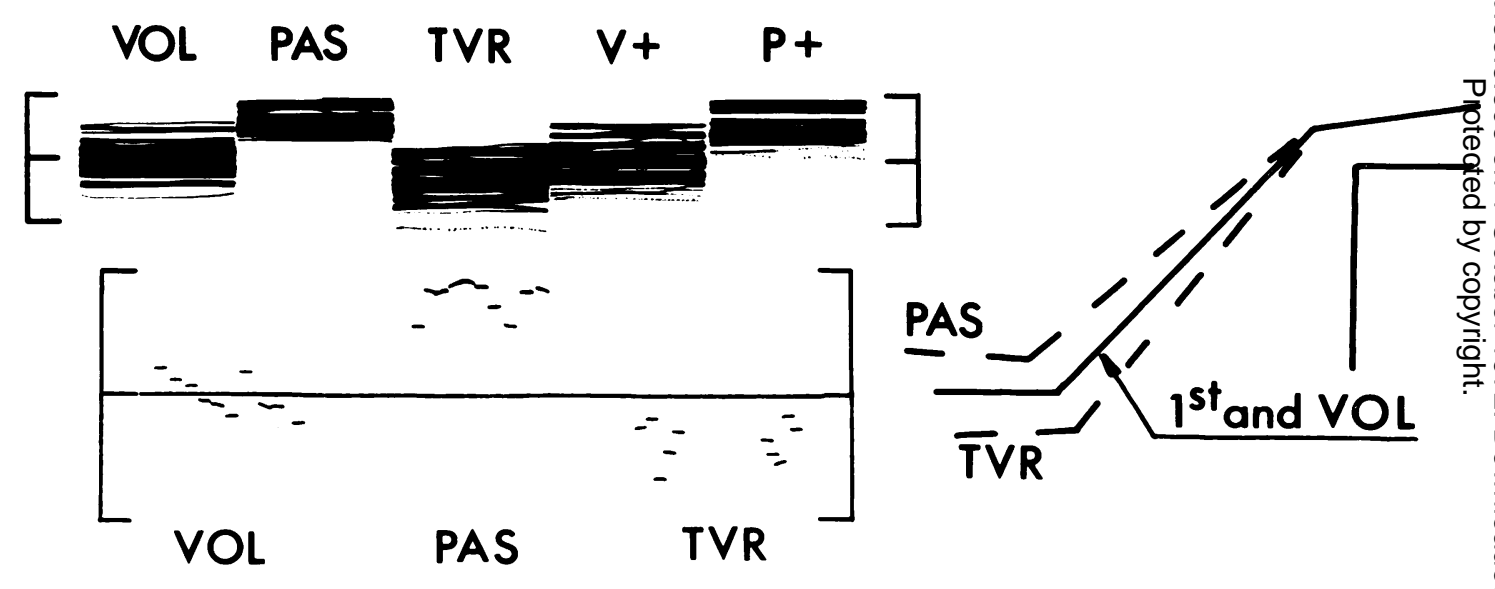

FIGURE To the right: a schematic summary of the general observations. To the left: the difference between the knee joint angles the moment the subject was content with his task. The indicator signal was used to trigger the sweeps; all 50 in upper row, the 10 first in the lower row. Note different amplification, calibration $0^{\circ}$ and $+1-10^{\circ}$. $V+$ and $P+$ stand for nonspecific vibration (see text) during VOL and PAS respectively.

TVR tended to become too strong during prolonged vibration. All the 50 values took 12 minutes to obtain during TVR, whereas VOL and PAS took only seven to eight minutes. The Figure shows the difference between the knee joint angles the moment the subject was content with his task. The signal from the indicator was used to trigger the oscilloscope sweep showing the difference between the two angle-signals. The was noted. Conversely, vibration of the flexor muscles gave a smaller extension than without vibration. It was also found that these manoeuvres performed during PAS or TVR as initially described, made the errors add. Thus, vibration of the flexors, for instance, exaggerated the underestimation of the position during TVR or diminished the tendency to overshoot during PAS. 


\section{DISCUSSION}

CONCEPT OF POSITION SENSE Information about position, movements, and forces is essential for motor control and is probably represented in suitable form at many levels in the central nervous system. Joint sense, deep sensation, proprioception, or whatever expression one prefers (Cohen, 1958b) are but descriptive terms for complicated sensory processes. These can utilize information from different types of receptors, the relative roles of which may be different in different parts of the body or, perhaps, different depending on what motor act they shall guide. The actual conscious awareness of a certain position is, more or less, a by-product of this information processing. It is chiefly served by joint receptors, but the possible contribution made by Golgi tendon organs or muscle spindles is not clear. According to Merton $(1964,1970)$, there is strong evidence that muscles are insentient in this respect. This view received support from the findings of Gelfan and Carter (1967). On the other hand, the notion that illusions of movements can be elicited by muscle vibration (Hagbarth and Eklund, 1966) is a strong indication that proprioceptors in muscles can contribute to conscious awareness of position.

TEST PROCEDURE The experimental procedures used involve the accuracy of position sense of the first leg, the corresponding mechanisms of the other leg and, in addition, the ability to compare the sensation of both sides. Thus, as pointed out by Cohen (1958a) the tests are not solely a task for the position sense in one joint. His method, instead, involved the memory of a certain position. The employment of indication with the second leg seems justified partly because qualitative rather than quantitative aspects of position sense were studied. For PAS and TVR, it should be noted that great care was undertaken to obtain good initial relaxation of the first legthat is, a state with no or smallest possible tendency towards unconscious contractions in limb muscles.

Information from sensory endings primarily not engaged in position sense may become significant, especially during prolonged and repeated tests. Therefore, in typical experiments the first observations are probably representative for the ability to use information primarily related to position sense. In fact, the average of the 10 first trials of the TVR-experiment (12 min long) amounted to $-3 \cdot 7^{\circ}$, which is more consistent with general observations than the result of all 50 trials $\left(-1.9^{\circ}\right)$. The reason for this 'improvement' with time, is probably that other clues had been utilized. The pressure of the back of the thigh against the edge of the bench is a rather obvious aid in the judgement of knee position during prolonged experiments. Thus, 'unwanted' sensory clues can contribute to the information used and are likely to become more prominent with time and practice.

POSSIBLE CAUSE FOR PAS-OVERSHOOT The present findings support those of Lloyd and Caldwell (1965) regarding the difference between VOL and PAS in the knee joints and are qualitatively the same as Paillard and Brouchon (1968) found regarding arm positioning-a position passively obtained is perceived as more extended than a voluntarily held position in the same range. Can this be due to a different inflow from joint and skin receptors? This is hardly a likely explanation, although Skoglund (1956) has shown that the joint receptor activity is partly dependent on the tension in the capsule evoked by the active pulling of the thigh muscles. It does not seem likely, however, that the information changes in a specific direction due to such a mechanism. Certain differences in afferent activity of skin receptors are not excluded. For instance, the pressure against the heel during PAS and the pressure against the back of the thigh during VOL are sources of additional clues which can probably affect the results, although it seems unlikely that they are solely responsible for the observed differences. The stretch receptors in the quadriceps muscle would certainly be more activated during VOL than they are in the PAS test situations. This applies to both Golgi tendon organs and muscle spindle afferents (Granit, 1970; Stuart, Mosher, and Gerlach, 1972). The difference in activity must be considered a possible major factor.

POSSIBLE CAUSE FOR TVR-UNDERSHOOT ${ }^{1}$ A position obtained by TVR in the quadriceps muscle

\footnotetext{
1 The difference between VOL and TVR has also been observed by Matthew's (personal communication) who investigated the corresponding circumstances in the elbow flexors. Thus, it is likely that the present principles are the same in the upper limb.
} 
is perceived as less extended than a voluntarily held position in the same range. In both cases (TVR and VOL) contractions of largely the same magnitude in the quadriceps muscle are responsible for the position and it is likely that joint receptors and receptors gauging contact-pressure send information that differs little. Certainly the vibration causes nonspecific stimulation of skin and probably periarticular receptors but such nonspecific stimulation did not notably affect position sense. Thus, joint and skin receptors can hardly be responsible for the difference. What about the muscle receptors? It is very likely that the vibration-induced sensory inflow is stronger than that accompanying the relatively weak, voluntary contraction. This is especially valid for IA afferent fibres.

If the sense of effort in the extensor muscles of the knee are compared as a part of the sensory process in question, the outcome of such a comparison would favour a curtailing of the indication movement before the accurate degree of extension is reached. Thus, the TVR in the first leg has no or very low effort-component which would call for too small an indication with the second leg, where the effort increases with the extension. Such a mechanism may possibly contribute to the TVR-undershoot but it should be noted that a similar mechanism cannot explain the overshooting in the PAS test which also implies a situation with no sense of effort in the first leg.

\section{CONCLUSION}

Information from proprioceptors in muscles seems to affect the sense of position. There is certainly strong evidence that a change of length in a relaxed muscle does not cause any sensation of new positions (Browne et al., 1954; Provins, 1958, Gelfan, and Carter, 1967; Merton, 1970). This does not exclude the possibility that inflow from active muscle can be significant for the sense of position. It does not contradict that tongue and eye muscles are insentient. Similarly, long forearm muscles acting on finger joints may well have a corresponding central arrangementthat is, sensory receptors outside the very muscle is the main afferent source. Thus, control of eye position, speech, and manipulation are motor acts different from posture and movement in conventional meaning. These different types of motor activities are likely to have different $\bar{Z}$ central mechanisms. There is experimental evidence that voluntary contractions in man are accompanied by fusimotor activity providing the necessary bias for a proper functioning of muscle spindle afferents and a prerequisite for $\stackrel{\infty}{S}$ the tonic stretch reflex (Hagbarth and Vallbo, 1968). In a corresponding way, it is conceivable $\stackrel{0}{\overrightarrow{2}}$ that the muscle becomes effective as a length- meter from a perceptual point of view only when $\overrightarrow{\vec{F}}$ it is properly innervated. There is neurophysio- $\overline{0}$ logical evidence that muscle spindle afferent fibres project to the cerebral cortex (for example, $\frac{\bar{D}}{\vec{D}}$ Albe-Fessard and Liebeskind, 1966) and whether $\stackrel{\square}{\square}$

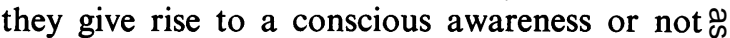
may depend on the existing state of excitability $\vec{\circ}$ of the cortical areas in question.

As mentioned above, the inflow from the $\vec{\omega}$ stretch receptors is probably low during PAS, intermediate during VOL, and high during TVR. This fact intimates a simple relation: high receptor activity (as during TVR) gives an illusion of $u$ the quadriceps muscle being longer (the knes more flexed), whereas low receptor activity ( o during PAS) gives an opposite illusion. All the findings in the present report, including those regarding vibration of the second leg, are consistent with this interpretation. A safe conclusio as to what receptor is the most important in thIs central processing of postural information mus 6 await further results.

\section{REFERENCES}

Albe-Fessard, D., and Liebeskind, J. (1966). Origine des messages somato-sensitifs activant les cellules du cortex moteur chez le singe. Experimental Brain Research, 1, $\rightarrow$ 127-146.

Browne, K., Lee, J., and Ring, P. A. (1954). The sensation of passive movement at the metatarso-phalangeal joint of the great toe in man. Journal of Physiology, 126, 448-458.

Cohen, L. A. (1958a). Analysis of position sense in human shoulder. Journal of Neurophysiology, 21, 550-562.

Cohen, L. A. (1958b). Contributions of tactile, musculo-? tendinous and joint mechanisms to position sense in $\bar{O}$ human shoulder. Journal of Neurophysiology, 21, 563-568.

Eklund, G. (1969). Influence of muscle vibration on balance in man. Acta Societatis Medicorum Upsaliensis, 74, 113- 긍 117.

Eklund, G. (1971). Some physical properties of muscle 음 vibrators used to elicit tonic proprioceptive reflexes in man. I Acta Societatis Medicorum Upsaliensis, 76, 271-280.

Eklund, G., and Hagbarth, K.-E. (1966). Normal variability of tonic vibration reflexes in man. Experimental Neurology, $\mathrm{N}$ 16, 80-92. 
Eklund, G., and Löfstedt, L. (1970). Bio-mechanical analysis of balance. Bio-medical Engineering, 5, 333-337.

Gelfan, S., and Carter, S. (1967). Muscle sense in man. Experimental Neurology, 18, 469-473.

Granit, R. (1970). The Basis of Motor Control. Academic Press: London.

Hagbarth, K.-E., and Eklund, G. (1966). Motor effects of vibratory muscle stimuli in man. In Muscular Afferents and Motor Control, pp. 177-186. Proceedings of the 1st Nobel Symposium, 1965, Södergarn. Edited by R. Granit. Almqvist and Wiksell: Stockholm.

Hagbarth, K.-E., and Vallbo, $\AA$. B. (1968). Discharge characteristics of human muscle afferents during muscle stretch and contraction. Experimental Neurology, 22, 674694.

Lloyd, A. J., and Caldwell, L. S. (1965). Accuracy of active and passive positioning of the leg on the basis of kinesthetic cues. Journal of Comparative and Physiological Psychology, 60, 102-106.

Merton, P. A. (1964). Human position sense and sense of effort. Symposia of the Society for Experimental Biology, 18, 387-400.

Merton, P. A. (1970). The sense of effort. In Breathing: Hering-Breuer Centenary Symposium, Ciba Federation Symposium. Edited by R. Porter, pp. 207-217. Churchill: London.

Paillard, J., and Brouchon, M. (1968). Active and passive movements in the calibration of position sense. In The Neuropsychology of Spatially Oriented Behavior. Edited by S. J. Freedman. Dorsey Press: Homewood, Ill.

Provins, K. A. (1958). The effect of peripheral nerve block on the appreciation and execution of finger movements. Journal of Physiology, 143, 55-67.

Skoglund, S. (1956). Anatomical and physiological studies of knee joint innervation in the cat. Acta Physiologica Scandinavica, 36, Suppl. 124.

Stuart, D. G., Mosher, C. G., and Gerlach, R. L. (1972). Properties and central connections of golgi tendon organs with special reference to locomotion. In Research Concepts in Muscle Development and the Muscle Spindle. International Congress Series No. 240. Excerpta Medica: Amsterdam. 